\title{
Simulation and Experimental Data of P-E Hysteresis Loop in BNT and BKT
}

\author{
Natheer B. Mahmood, Emad K. Al-Shakarchi \\ Physics Department, College of Science, Al-Nahrain University, Baghdad, Iraq \\ Email:eks2000@hotmail.com
}

How to cite this paper: Mahmood, N.B. and Al-Shakarchi, E.K. (2017) Simulation and Experimental Data of P-E Hysteresis Loop in BNT and BKT. Journal of Modern Physics, 8, 844-851. https://doi.org/10.4236/jmp.2017.85053

Received: March 23, 2017

Accepted: April 25, 2017

Published: April 30, 2017

Copyright $\odot 2017$ by authors and Scientific Research Publishing Inc. This work is licensed under the Creative Commons Attribution International License (CC BY 4.0).

http://creativecommons.org/licenses/by/4.0/

(c) (i) Open Access

\begin{abstract}
Hysteresis loop measurements performed both experimentally for Bismuth Sodium Titanate (BNT) and Bismuth Potassium Titanate (BKT) samples using modified Sawyer-Tower Circuit. The experiment showed that the P-E hysteresis had main parameters for $\mathrm{BNT}$, remnant polarization $\left(P_{r}=27\right.$ $\left.\mu \mathrm{C} / \mathrm{cm}^{2}\right)$, spontaneous polarization $\left(P_{s}=35 \mu \mathrm{C} / \mathrm{cm}^{2}\right)$ and coercive electric field $\left(E_{c}=60 \mathrm{kV} / \mathrm{cm}\right)$ and for BKT the remnant polarization was $\left(P_{r}=5.2 \mu \mathrm{C} / \mathrm{cm}^{2}\right)$, spontaneous polarization $\left(P_{s}=30 \mu \mathrm{C} / \mathrm{cm}^{2}\right)$ and coercive electric field $\left(E_{c}=\right.$ $4.72 \mathrm{kV} / \mathrm{cm}$ ). These three parameters (remnant polarization, spontaneous polarization, coercive electric field) were used in a simulated software depending on the mathematical model for the polarization in ferroelectric materials. The simulation software predicted the value of applied electric field required to perform the P-E hysteresis experiment varying with $P_{r}, P_{s}, E_{c}$ The results of the simulation exhibited agreement with the experimental data. The last prediction could help the researchers in studying the ferroelectric hysteresis loop, especially for those studying a fatigue behaviour or studying the effect of electric field cycle on the hysteresis loop.
\end{abstract}

\section{Keywords}

Ferroelectric Behaviour, Fatigue Behaviour, Hysteresis Loop, Perovskite Structure

\section{Introduction}

Ferroelectric materials are materials possessing spontaneous polarization, which can be reversed by applying of an external electric field over a certain temperature range [1]. The most prominent features of ferroelectric properties are hysteresis and nonlinearity in the relation between the polarization $\mathrm{P}$ and the applied electric field $\mathrm{E}$. The ferroelectric material has a perovskite structure with the formula of $\mathrm{ABX}_{3}$, the cations $(\mathrm{A}, \mathrm{B})$ have a different sizes and the anion $(\mathrm{X})$ 
is normally Oxygen ion [2]. The oxygen octahedral perovskite structure has the formula $\mathrm{ABO}_{3}$, and it was considered a promising material because the spontaneous polarization is greater than in other ferroelectric families [3]. In this research, the BNT ceramic like $\mathrm{Bi}_{0.5} \mathrm{Na}_{0.5} \mathrm{TiO}_{3}$ and $\mathrm{BKT}$ ceramic like $\mathrm{Bi}_{0.5} \mathrm{~K}_{0.5} \mathrm{TiO}_{3}$ were used to study the hysteresis loop and measuring the polarization as a function of electric field by using Sawyer-Tower circuit. The parameters remnant polarization, spontaneous polarization and coercive electric field measured by Sawyer-Tower circuit were used in the simulation program. The simulation program could help researchers to perform the hysteresis loop experiment and polarization fatigue, which help us perform the experimental parameters, especially for the polarization fatigue analysis and measuring polarization fatigue life. A comparison between experiment and theory could help to understand the Polarization behaviour and polarization domain dynamics.

\section{Experimental Work}

The hysteresis loop measurements during (P-E) loop were studied for ferroelectric ceramic Bismuth Sodium Titanate (BNT) and Bismuth Potassium Titanate (BKT) by using modified Sawyer-Tower circuit, as shown in Figure 1. The Sawyer-Tower circuit is consists the following items;

1) High voltage AC Power Supply has the specification $(0-10 \mathrm{kV}), 0.5 \mathrm{~A}$, sine wave and frequency $50 \mathrm{~Hz}$ [4]

2) The voltage divider acts as voltage attenuator, and the voltage attenuation calculated according to the equation

$$
V(x)=V_{\text {in }} \times \frac{R_{2}}{R_{2}+R_{1}}=V_{\text {in }} \times \frac{2.2}{2.2+220} \approx \frac{1}{100} \times V_{\text {in }}
$$

3) The capacitor of $(0.68 \mu \mathrm{F})$ was used.

4) The sample that used in this experiment was sandwiched between two gold electrodes as shown in Figure 2, and dipped in low viscosity oil (Silicon oil) to prevent discharge due to high voltage.

5) The digital storage oscilloscope type Tektronix TBS 1000 was used to ac-

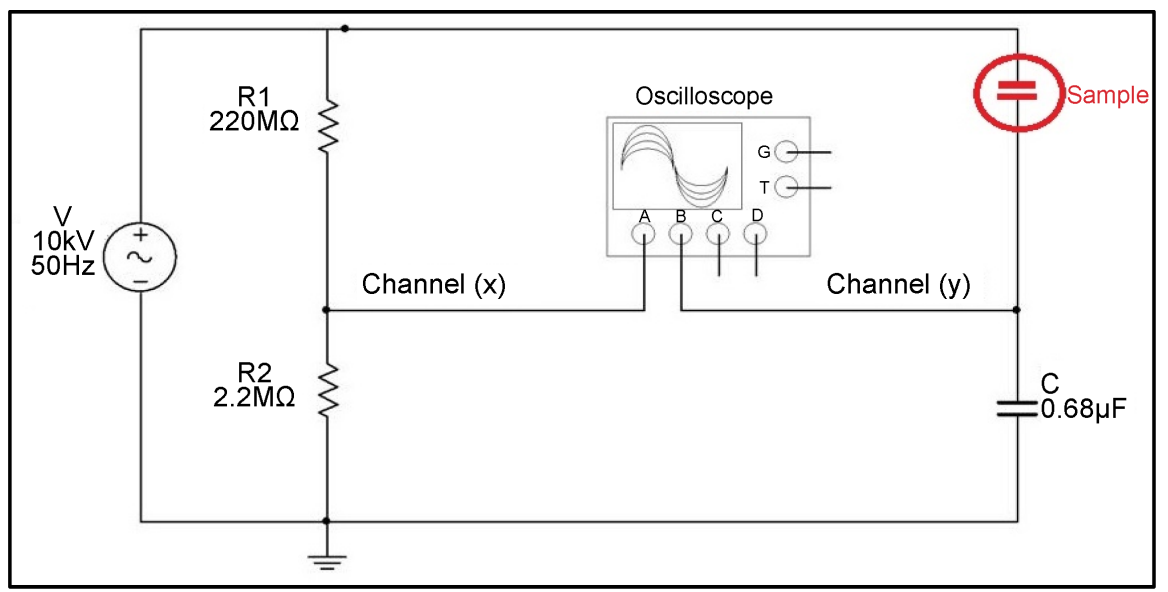

Figure 1. Schematic of the experimental setup for Sawyer-Tower circuit. 


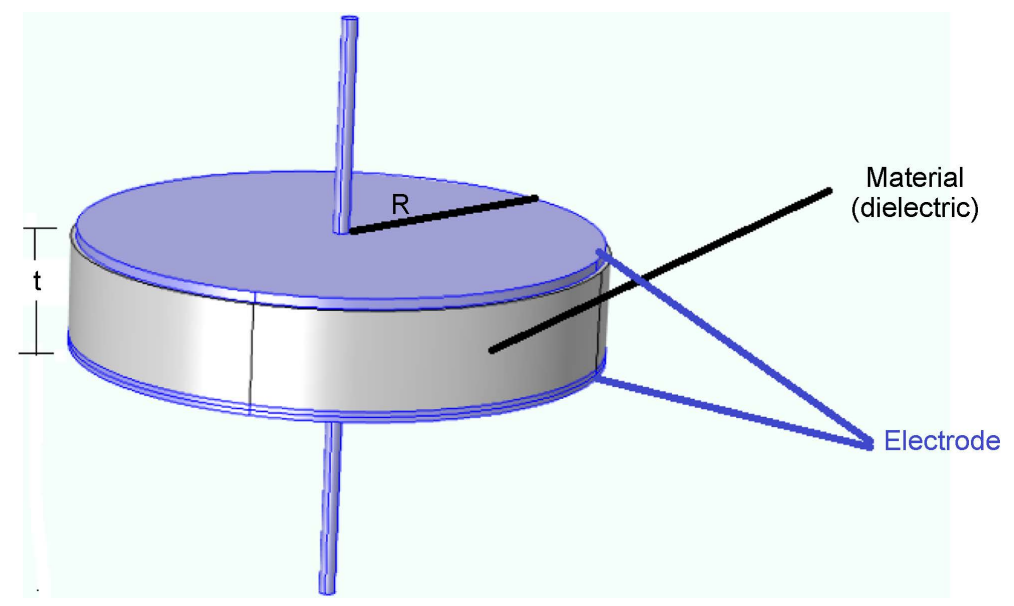

Figure 2. The sandwiched sample under test.

quire the signals with some modifications on both value of $x-y$ axes, such that the $\mathrm{x}$-axis is the Electric field $(\mathrm{kV} / \mathrm{cm})$ calculated by the following equation;

$$
E\left(\frac{\mathrm{kV}}{\mathrm{cm}}\right)=\frac{V_{\text {division }}(\mathrm{V}) \times 100 \times 0.001}{t(\mathrm{~cm})}
$$

The $y$-axis is the polarization $\left(\mu \mathrm{C} / \mathrm{cm}^{2}\right)$ calculated in the following equation;

$$
P\left(\frac{\mu \mathrm{C}}{\mathrm{cm}^{2}}\right)=\frac{V_{\text {division }} \times 10^{6} \times C(\mathrm{~F})}{\text { Area }\left(\mathrm{cm}^{2}\right)}=V_{\text {division }} \times \frac{0.68}{\pi r^{2}}
$$

where the parameters $(r, t)$ are the radius and the thickness of the ceramic disc sandwiched between two electrodes respectively.

The hysteresis loop measurement had been done by increasing the voltage gradually to get the curve of the hysteresis, then the saturation polarization $\left(P_{s}\right)$, Remnant polarization $\left(P_{r}\right)$, and coercive electric field $\left(E_{c}\right)$ were measured. The simulation of hysteresis loop was performed by designing a program using LabView2016 depending on the mathematical model of (P-E) loop by the following equation [5] [6] [7];

$$
P= \pm P_{s} \tanh \left(\frac{ \pm E-E_{c}}{2 \delta}\right)
$$

The parameter $(P)$ is the polarization, the positive sign is referring to positive polarization $P^{+}(E)$, while the negative sign refers to negative polarization $P^{-}(E)$, such that $P^{-}(E)=-P^{+}(E)$ by the symmetry. The parameter $(E)$ is the applied electric field, and $\left(E_{c}\right)$ is the coercive electric field. The factor $(\delta)$ is a polarization relaxation coefficient and calculating according to the following equation;

$$
\delta=E_{c}\left[\ln \left(\frac{1+P_{r} / P_{s}}{1-P_{r} / P_{s}}\right)\right]^{-1}
$$

The factor $\left(P_{r}\right)$ is remnant polarization, and $\left(P_{s}\right)$ is the saturation polarization. The study started by changing the values of the electric field from negative to positive by gradual steps. The input data for the simulation is represented by a 
maximum applied electric field $\left(E_{\max }\right), E_{\mathcal{c}} P_{r}, P_{s}$, and number of steps ( $>100$ steps normally). The output data is the P-E loop as a graph and table, which could be saved with different extensions as excel file, Matlab or Origin profile.

\section{Results and Discussion}

The hysteresis loop for ferroelectric ceramic was performed using modified Sawyer-Tower circuit at $50 \mathrm{~Hz}$ using adjustable AC power supply as mentioned before. The polarization as a function electric field was plotted as a result from the output of the oscilloscope and estimate the remnant polarization $\left(P_{r}\right)$, spontaneous polarization $\left(P_{s}\right)$, and coercive electric field $\left(E_{c}\right)$ for each sample. The Sawyer-Tower circuit was modified by adding the voltage divider to attenuate voltage by a factor of $0.01 \mathrm{~V}$ in order to prevent oscilloscope from damage. If the maximum applied voltage is $(10 \mathrm{kV})$ then the voltage appeared on the oscilloscope will be $(100 \mathrm{~V})$, attenuated by a factor 0.01 . The normal capacitor $(0.68 \mu \mathrm{F})$ was used, such that it was greater than the sample capacitance by (100) time, which was about $(300 \mathrm{pF})$. The high capacitor connected in series has low voltage comparing with a low capacitor that possess high voltage where $V_{\text {total }}=V_{1}+V_{2}$. If the applied voltage on both capacitors in series was $(10 \mathrm{kV})$, so the voltage on the normal capacitor $(0.68 \mu \mathrm{F})$ will be $5 \mathrm{~V}$, while the voltage on the sample will be $9995 \mathrm{~V}$. Most of the applied voltage exerted on the sample that was very important because one could be apply more than the twice coercive electric field on the sample in order to get a sharp hysteresis loop.

The estimated values of $\left(P_{r}, P_{s}\right.$ and $\left.E_{c}\right)$ were used in the computer simulation as inputs, the obtainable results from the simulation is transferred into the hysteresis shape at the same value of $P_{r}, P_{s}$ and $E_{c}$ The simulation could help us to predict the applied electric field values required for experimental work. The user interface of (P-E) loop that was designed in this research is shown in Figure 3.

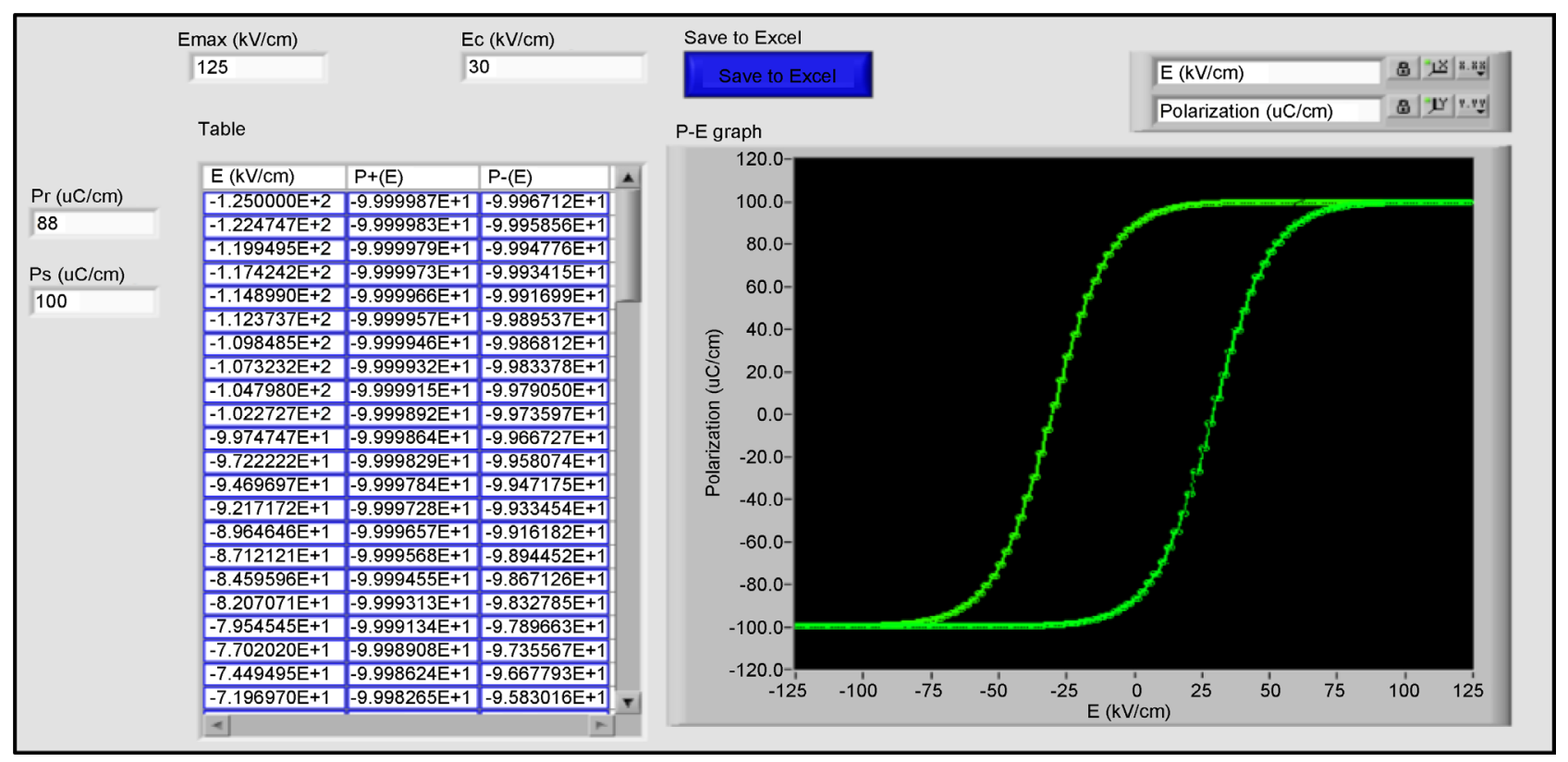

Figure 3. The user interface for hysteresis loop simulation. 
The simulated variable was the electric field on the $\mathrm{x}$-axis and the polarization on the y-axis. Therefore, the changing with the electric field value from negative to positive was dependent by $N$-step divided on the x-axis, normally $N>100$ steps using the following equation inside the loop.

$$
E=E_{a}\left(\frac{2 i}{N-1}-1\right)
$$

The factor $\left(E_{a}\right)$ is the applied electric field value, which is actually has the maximum value $\left(E_{\max }\right)$. The above equation performed as an electric field sweep kit, shown in Figure 4. For example $N=100$ steps, for $i=0$ so $E=-E_{a}$, for $i=1$ so $E=-0.9 E_{a}$ and for $i=99$ so $E=+E_{a}$ (100 steps means $i=0$ to 99 ). The second variable, the polarization was performed as a kit depending on the Equation (1), as shown in Figure 5. The simulated block diagram of (P-E) hysteresis loop is collected into a single program as shown in Figure 6.

The simulation was important to solve many problem, the first one was the value of the applied electric field, a lot of researches had chosen the applied electric field value by increasing the voltage until the hystersis loop appeared [8]. They were adviced to use the applied electric field by $\left(2 E_{c}\right)[8]$ [9] [10], because it was required a totally reversing the polarization. This value is correct in the case $P_{s}=$ $P_{r}$ only [10] [11]. Our analysis is predicted the applied electric field value to be $\left(\eta E_{c}\right)$, where the parameter $(\eta)$ is depending on the ratio $P_{s} / P_{r}$, i.e. linearly dependent on $(\delta)$. The values of the applied electric field are symmetric that making $P^{+}(E)=P^{-}(E)$, as mentioned in the Equation (1). The simulation had

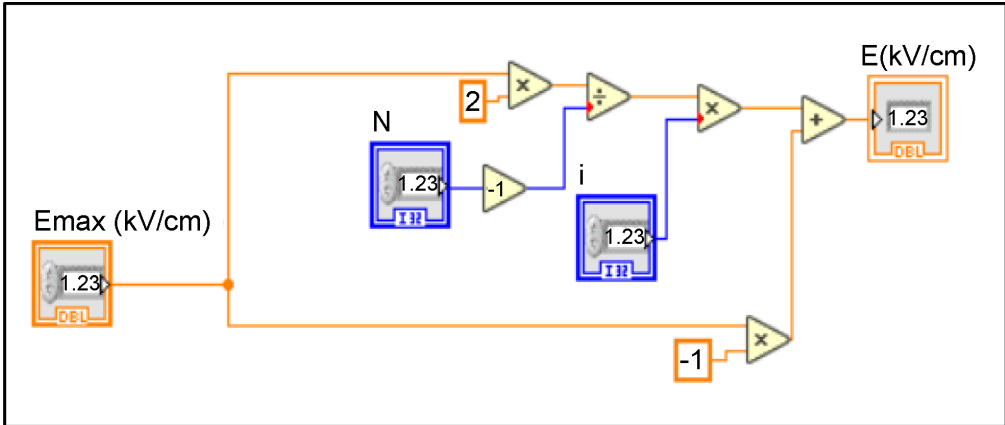

Figure 4. The electric field sweep kit.

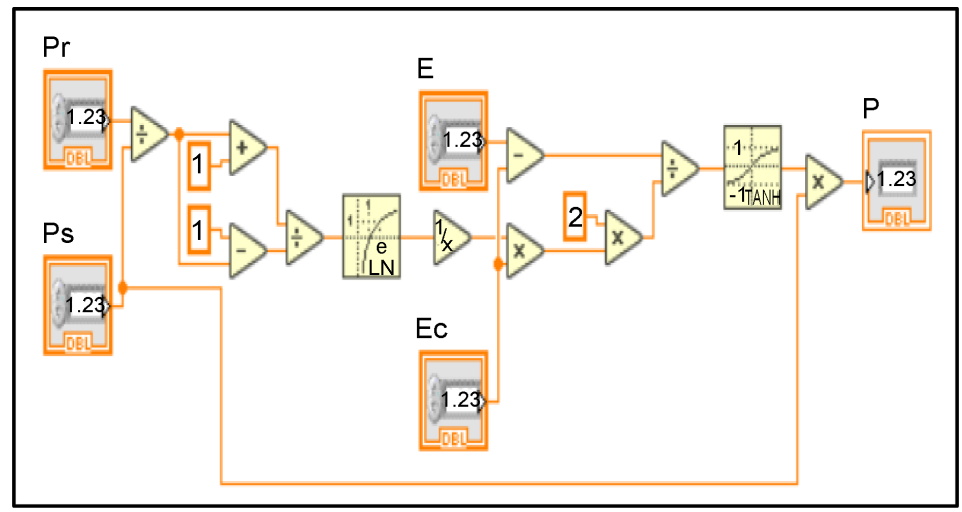

Figure 5. The block diagram for polarization kit. 
been done depending on the Equation (2), to predict the applied electric field and then the polarization, using the stop condition if $P^{+}(E)=P^{-}(E)$. The user interface of the simulated program to predict the electric field is shown in Figure 7. The results for the applied electric field showed a linearly dependance on the value of the polarization relaxation coefficient $(\delta)$ i.e. the differences in $\left(P_{r}\right)$ and $\left(P_{s}\right)$ is leading to vary the $\delta$-value, which lead to change the value of the applied electric field $\left(E_{a}\right)$ as shown in Figure 8. The fitting curve concluded the predicted electric field value by the following equations;

$$
\begin{gathered}
E_{a}=E_{c}(1+7.4 \delta) \\
\eta=(1+7.4 \delta)
\end{gathered}
$$

The experimental data of (P-E) hysteresis loop for BNT-ceramic are shown in Figure 9(a). It had the values $P_{r}=27 \mu \mathrm{C} / \mathrm{cm}^{2}, P_{s}=35 \mu \mathrm{C} / \mathrm{cm}^{2}$, and $E_{c}=60$

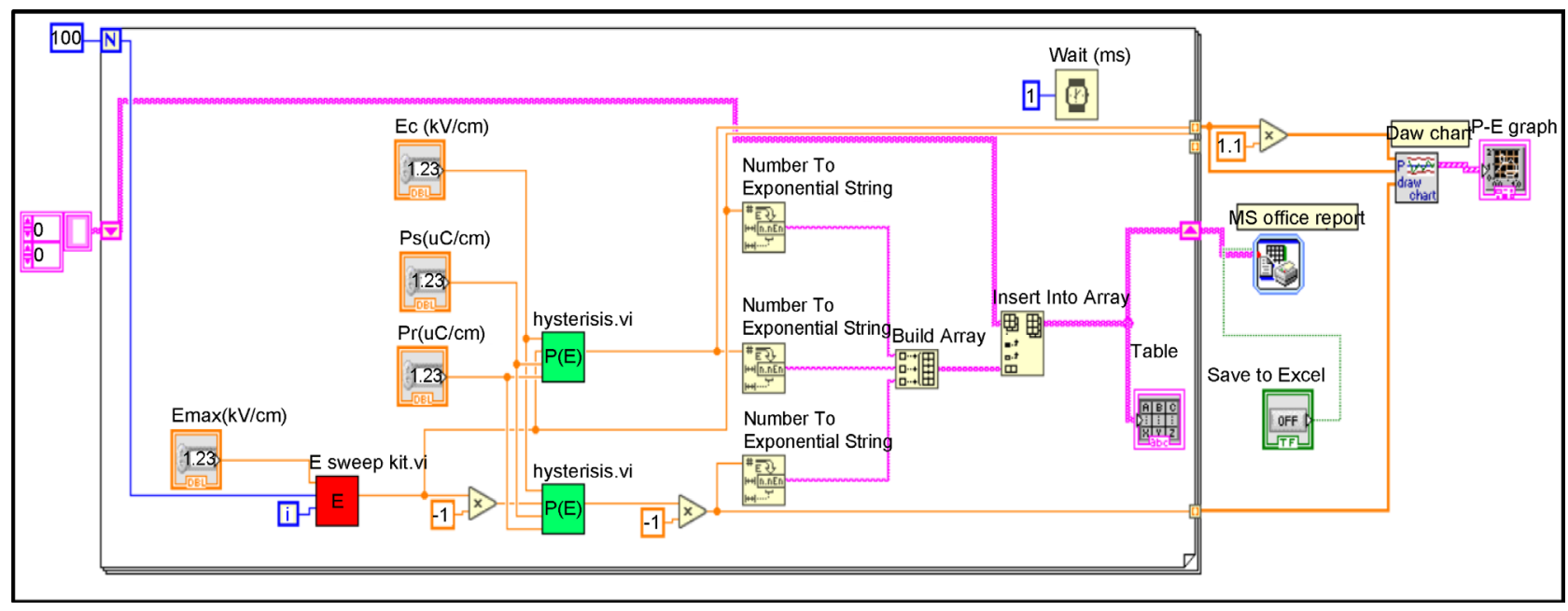

Figure 6. The block diagram of the P-E hysteresis loop.

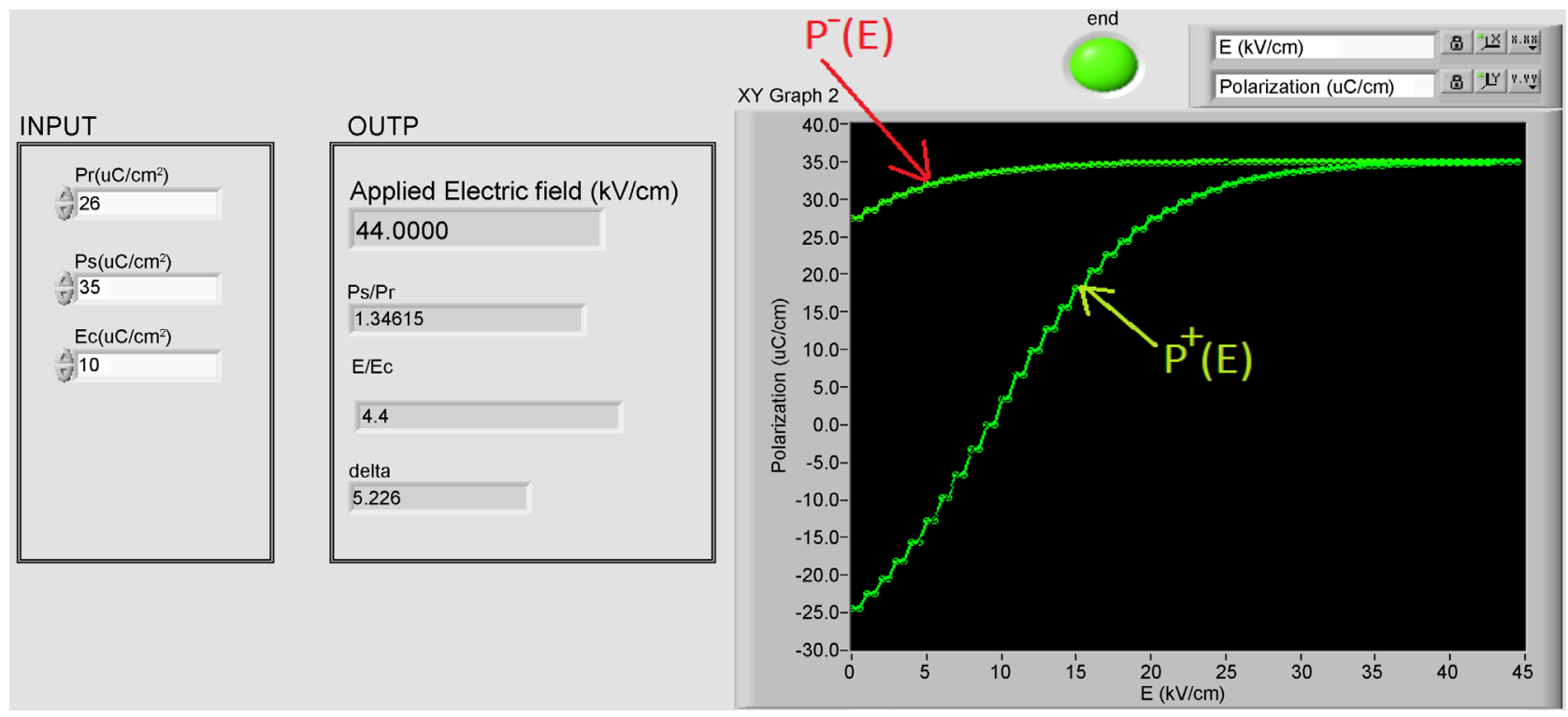

Figure 7. The program kit for prediction the applied electric field. 
$\mathrm{kV} / \mathrm{cm}$. Whereas the simulated curve had the similar values of $P_{r}, P_{s}$ and $E_{c}$ are shown in Figure 9(b), with the predicted value of $E_{a}=257 \mathrm{kV} / \mathrm{cm}$. The BKT sample was exhibited the experimental values of polarization and electric field with $P_{r}=5.2 \mu \mathrm{C} / \mathrm{cm}^{2}, P_{s}=30 \mu \mathrm{C} / \mathrm{cm}^{2}$ and $E_{c}=4.72 \mathrm{kV} / \mathrm{cm}$, as shown in Figure 10(a). Whereas the simulated curve with the same values of $P_{r}, P_{s}$ and $E_{c}$ is shown in Figure 10(b) with the predicted value of $E_{a}=81 \mathrm{kV} / \mathrm{cm}$. The predicted values of applied electric field of BNT sample was about $4.18 E_{c}$ i.e. $\eta=4.18$.

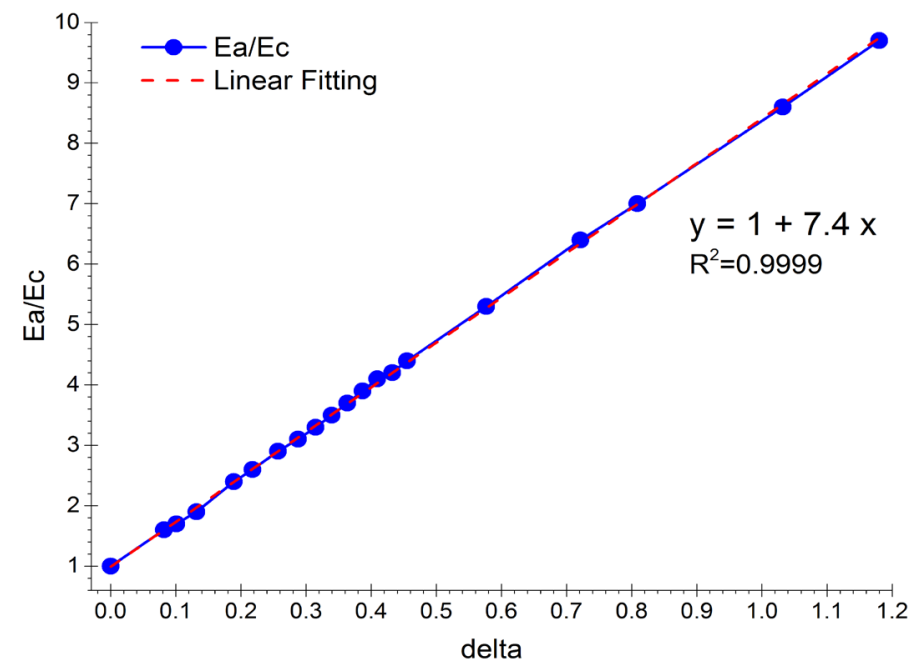

Figure 8. The predicted applied electric field value as a function of the polarization relaxation coefficient.
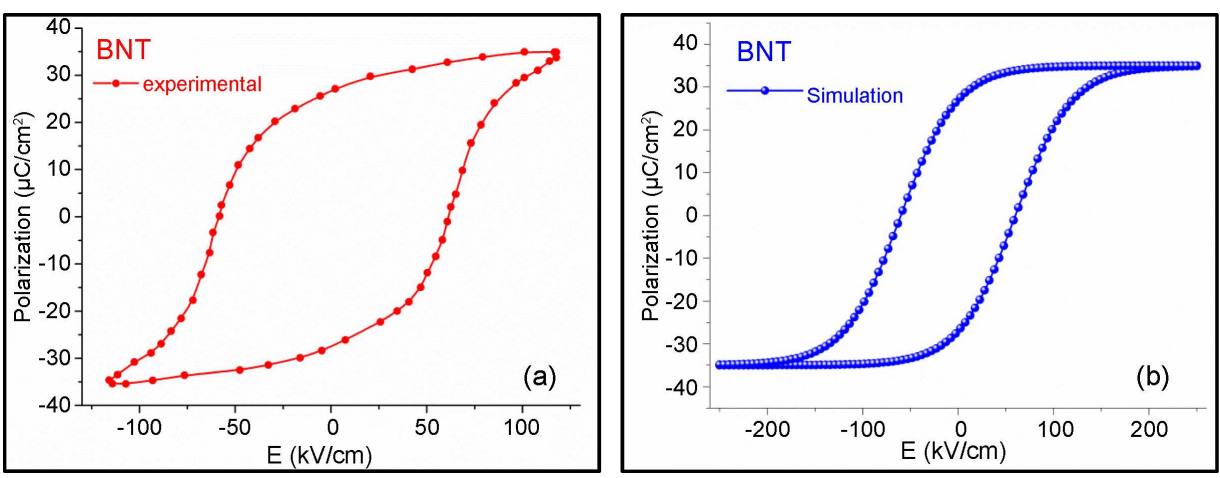

Figure 9. The (P-E) hysteresis loop for BNT sample (a) experimental (b) simulation.
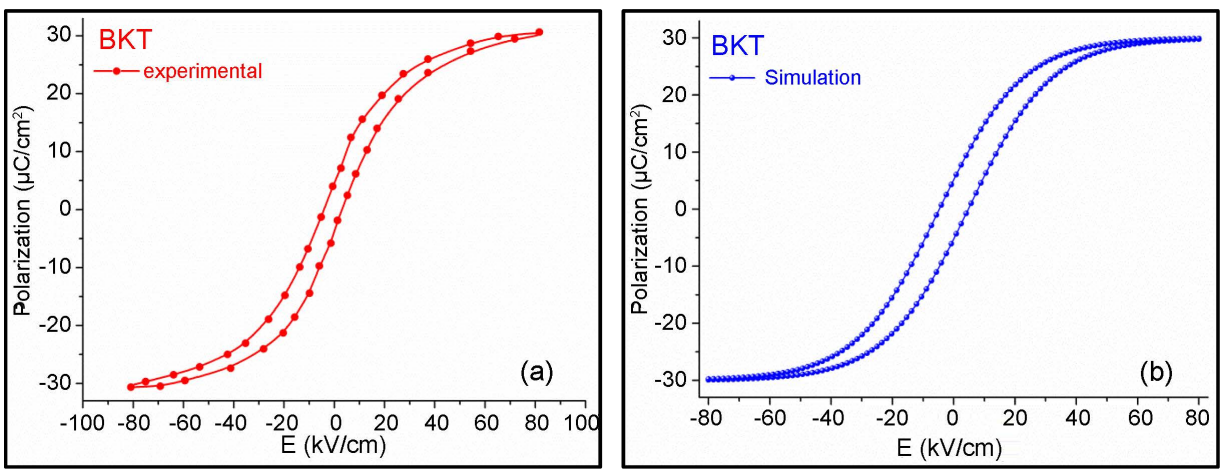

Figure 10. The (P-E) hysteresis loop for BKT sample (a) experimental (b) simulation. 
Whereas the predicted value of applied electric field of BKT sample was about $17.1 E_{c}$ i.e. $\eta=17.1$. The last results for BKT were agreed with the experiments, while for BNT sample was not clear because it is difficult to apply an electric field $>100 \mathrm{kV} / \mathrm{cm}$ due to the limitation of the power supply.

\section{Conclusion}

The hysteresis loop experiment is an important analysis to determine the value of polarization and the coercive electric field on the dielectric media. It was a successful technique to simulate the hysteresis loop experiment depending on the required mathematical equations in polarization of ferroelectric materials. The simulation results showed agreement with experimental output. It was considered to predict the applied electric field values those were used in hysteresis experiment and formulating an equation describing the change in the applied electric field. The last prediction could help the researchers to study the ferroelectric hysteresis loop, especially for those who suffering fatigue or studying the effect of electric field cycle on hysteresis loop.

\section{References}

[1] Kao, K.C. (2004) Dielectric Phenomena in Solid. Elsevier Academic Press, Amsterdam.

[2] Mahmood, N., Al-Shakarchi, E. and Elouadi, B. (2012) Barium Strontium Titanate. Lambert Academic Press, Saarbrücken.

[3] Uchino, K. (2010) Advanced Piezoelectric Materials: Science and Technology. Elsevier Academic Press, Amsterdam. https://doi.org/10.1533/9781845699758

[4] Al-Shammary, B.H.H. (2014) Construction and Characterization of Pseudospark High Power Plasma Switch. PhD Thesis, Physics Department/College of Science/AlNahrain University, Baghdad.

[5] Raye, J.K. and Smith, R.C. (2004) Parameter Estimation Techniques for Nonlinear Hysteresis Models. Smart Structures and Materials 2004, Proceedings of SPIE, Vol. 5383, Bellingham, 155-163.

[6] Lupascu, D.C. (2004) Fatigue in Ferroelectric Ceramics and Related Issues. Series in Materials Science 61, Springer, Berlin. https://doi.org/10.1007/978-3-662-07189-2

[7] Sheikholeslami, A. (1997) IEEE Transactions on Ultrasonics, 44, 917-924. https://doi.org/10.1109/58.655207

[8] Kampoosiri, S., Pojprapai, S., Yimnirunand, R., and Marungsri, B. (2012) International Journal of Electrical, Computer, Energetic, Electronic and Communication Engineering, 6, 1456-1460.

[9] Stewart, M., Cain, M.G. and Hall, D.A. (1999) Ferroelectric Hysteresis Measurement and Analysis. NPL Report CMMT(A) 152.

[10] Yoshimura, T. and Fujmura, N. (2003) Japanese Journal of Applied Physic, 42, 6011-6014. https://doi.org/10.1143/JJAP.42.6011

[11] Reece, T.J. and Ducharme, S. (2009) Journal of Applied Physics, 106, Article ID: 124505. https://doi.org/10.1063/1.3271581 
Submit or recommend next manuscript to SCIRP and we will provide best service for you:

Accepting pre-submission inquiries through Email, Facebook, LinkedIn, Twitter, etc. A wide selection of journals (inclusive of 9 subjects, more than 200 journals)

Providing 24-hour high-quality service

User-friendly online submission system

Fair and swift peer-review system

Efficient typesetting and proofreading procedure

Display of the result of downloads and visits, as well as the number of cited articles Maximum dissemination of your research work

Submit your manuscript at: http://papersubmission.scirp.org/

Or contact jmp@scirp.org 